\title{
Teaching Reform for Mechanics of Materials Based on the CDIO Education Concept
}

\author{
Zhenhua Liu \\ Mechanical Engineering College, Xi'an Shiyou University, Xi'an, 710065, China \\ e-mail: liuzhenhua@xsyu.edu.cn
}

Keywords: Teaching; CDIO concept; Capacity-building

\begin{abstract}
Due to the ability target in the teaching of material mechanics course is not clear, the CDIO education concept in engineering was introduced to increase the refining capacity development objectives. The "experiencing entire process of solving a problem" and other capacity-building ways were suggested. The present practices achieved satisfied teaching effects.
\end{abstract}

\section{Introduction}

CDIO means an engineering education model [1] with conceive, design, implement and operation. It provides the cycle of products or systems from research, development to operation as the carrier to trains students' engineering ability in order to meet the demands of modern industrial engineering quality.

CDIO education idea was realized through the CDIO syllabus and standards [2]. It refined the knowledge, ability and quality, which are necessary for an engineer, step by step for more than more than 400 items. It integrates the training goals into the undergratuate student training programmes. Gernally, the undergraduate course was $60 \sim 70 \%$ in total teaching plan; hence the treaching quality is very important to achieve the CDIO engineering education goals.

The mechanics of materials is a basic technique course with a strong engineering background; however, during the teaching, the capacity-building issues is not very clear. The CDIO concepts were applied to the teaching reform of engineering education, then to find an effective way to achieve the goal of CDIO refine training in the practical course teaching.

\section{The Problems and Reform Thinking in the Teaching of Mechanics of Material}

One of the main purposes of the course is to teach knowledge. Not only CDIO mode doesn't weaken the technical knowledge requirements, but also it enhances the integration training of knowledge application, capability and quality. In CDIO teaching mode, the knowledge and ability goal for engineering education were refined to the items that can be observed and evaluated during every training step. It provides implementation requirements and guidelines for CDIO education aims [3-5].

The course syllabus of mechanics of materials listed teaching content and basic requirements in detail; but its claims about the capacity-building was less refined. It only broadly described as: computing ability, some skill abilities to analyze and solve problems, and experiment ability.

Although teachers can understand the importance of capacity building, teaching process lacks specific goals and standards since the syllabus dose not provide detail demands for capacity, so that both the aims and standard lacked during teaching process. It results in the ability-building implementation will not be easy to get real. Therefore, courses reform ought to begin from syllabus revision. A new item, basic requirements for personal capacity, was increased in the original courses syllabus content. This new item gave a wide range of capacity-building objectives that can be carried out.

The present new items that are basic requirements for personal capacity, include some abilities as following: (1) founding and expressing problems, (2) establishing mechanics model, (3) estimating and analyzing qualitatively, (4) performing and modification, (5) creative thinking, (6) criticism thinking, (7) establishing assumptions, (8) literature index, (9) exploration during experiments, (10) 
self study, (11) expression and exchange, and so on. Also, more than 30 items of refinement requirements corresponding to the basic requirements for personal capacity were established. For this refinement capacity targets, the effective teaching modes were established to exploration the ways of combination the capacity training with classic courses teaching process.

\section{The Reform Practice of Mechanics of Materials Course}

To achieve the ability training objectives in revised course syllabus of mechanics of materials, the teaching methods for teachers and learning patterns for students were reform simultaneously. The present practice focused on some requirements that were neglected in previous teaching. Following were the ways of refining capacity-building.

\section{Teaching design based on "creative thinking"}

Innovation or creative thinking ability is often expressed as: the ability to put forward a new theory, to make new inventions and new product development. Obviously, it is difficult to do some innovation for undergraduate students who are still in the study stage of basic courses. The "creative thinking" in CDIO outline is defined as: possessing the ability to conceptualize and abstract; a comprehensive and universal capabilities; explaining the process of the invention; discussing the role of creativity in the arts, sciences, humanities and technology. These definitions in CDIO about innovation ability are achievable in course teaching of mechanics of material.

Conceptualization and abstraction ability. There are more concepts in mechanics of materials course. The usual teaching method is to introduce a concept directly; then to explain it. Students are also used to remember concepts and understand them. They are less likely to have awareness of concept formation. This shows the inadequate attention to the concept formation process. In the present teaching, the teaching method of giving concepts directly was replaced by guiding students to establish new concepts and to develop the ability to conceptualize by observing, thinking, refining and so on. Such as the buckling concept teaching, teacher first let the students observe the slender rod bent, then to analyze it as a bending problem, a combination of bending deformation, or new problems? At last, teacher guides student to establish the concept with essential characteristics for the problem and to form the concept of compression bar stability. In teaching, the teacher should let the students realize that "put forward a new concept" is a very important innovation. It requires students to pay attention to the process of establishing the concept, and not just limited to the understanding of the concept.

Explain the invention process. Due to limited class hours, the process of a technical invention was used to introduce in fewer time. Now the invention introduction related to the course content was increased. For example, the process of a technical invention for I-beams with corrugated web. It experiences the change from flat slab corrugated steel plate to I-beams with corrugated web. The invention used the most basic mechanical principles. When the section of a material is placed far away from the neutral axis of section, the bending strength of the section to the neutral axis is higher. Therefore, introduction of the invention process can strengthen the understanding to the course content for students. It is also helpful for students to understand the application of mechanical principle in the promotion of technological innovation. As well, it will be helpful for students to understand the evolution and possibilities of technological development. This is very important for the building of creative ability.

The teaching design based on the "ability to establish hypothesis" training.

For "ability to establish hypothesis", CDIO outline lists the rules: to select the key issues that need to be verified; to establish the hypothesis that need to test; to discuss the comparison group.

For the analysis of pure bending stress in mechanics of material, in previous practice of teaching, a sponge was a teaching aid to be used to observe the surface deformation after applying the bending moment. Since the deformation of sponge is obviously, the assumption of plane can be given at once based on the deformation prediction. However, there is no comparison, this deformation and prediction is very easy to get. In order to strengthen the students' attention on establishment hypothesis, the comparison group was discussed. First, cardboard aids was use to observe the deformation after applying bending moment. Deformation can not be observed 
intuitively. Thus, a question was introduced that if no visible deformation can be assumed as uniform deformation? Then, the sponge was used as aids to show the deformation characteristic that was significant. What is the character of real deformation? Historically, the bending deformation was given by Galileo. It provided for a uniform deformation, which was confirmed inconsistent with the facts later. For the important plan prediction and deformation in the bending deformation, the teaching method of comparison group can enable students to find questions, furthermore to think and discuss them. At last students will understand that the correctness of assumptions plays a decisive role to obtain correct conclusions.

\section{To add practical problems and cultivate more capacity}

The CDIO syllabus of education requires teachers not only to teach students knowledge, but also to cultivate students' abilities. It is not only necessary to reform classroom teaching method, and also to reform the mode of students' learning. For a student, the learning process usually includes listening the course in class, reading books, and doing homework. The effect of study was mainly reflected by ones homework. The most homework of mechanics of material was the type of simulation, in which the model, determination of the original data, and standard answer were given. Students only need to apply their theoretical knowledge to solve these problems.

The CDIO syllabus listed the specific requirements for building model, assessment data, analysis assumptions and source of bias, estimating order of magnitude and range, forming summary of recommendations, listing references, and so on. It is clear that the current learning style is defective to achieve a wide range of ability training objectives. Students' learning initiative is obviously insufficient. In the present teaching reform practices, students do these topics in initiative and practical way in grouping assignment. For example, a topic "a piece of paper", which gives that there are three kinds of placement for a paper: heel, flat, V-shaped fold. By its own weight, its maximum stress and maximum deflection need to be calculated and compared. Another topic is to determining the stresses of both the core and the outer wood layer under pressure. To complete this kind of problems, students need to go through the entire solving process, which includes establishing model, determining related data and recording source of each data, solving problem from theoretical methods, analyzing results, and writing calculation books.

\section{The Effects of Reform Implementation}

The ability training objectives were refined in the new present syllabus of the mechanics of materials. It gives the new definition of the capacity goal that was ignored in previous teaching, so that the training objectives become more comprehensive and specific.

In class teaching, the capacity training was carried into the process of teaching knowledge by various teaching design. Some capacity training methods were suggested for refining capacity target. Good teaching effects were made for these ways. In the present teaching practices students no longer just care the process of getting knowledge; also they pay more attention to the exercise and improvement in capacity. Better interactive and exchange happened between students and teachers. It is helpful for achieving the integration training purpose of knowledge and capacity.

The practical problems, witch were designed for students' homework, deal with real visible objects; so that they have greater coverage. However, these topics have few limit conditions and no any answer was given; hence students' learning interest was stimulated effectively. During the experience of entire problem-solving process, students' perceptual knowledge was improved and the understanding on the courses content was enhanced. Also, the ability of establishing model, proposing assumptions, accessing to information, assessing data, observing and analyzing, evaluating results, working together with others, and so on, were enhanced.

In the entire process of solving problem, students can experienced various situations that could not be encountered from idealized calculation models. Therefore, the full solution process provides students opportunities to find, analysis from multiple views, and solute problem independently. As well, they learn much from mistakes. They generally feel it is a great learning way.

From CDIO teaching reform of the present course, not only students can master the basic knowledge listed in curriculum outline, but their multiple abilities are trained; so that the ability 
training becomes workable and vague requirements can be avoided.

\section{Conclusions}

The detail ability syllabus can guide the reform of both teaching mode and teaching method. It suggests that the teaching reform pay attention to the subtle items and to build active learning environment for students.

Practical topic can enable students to enhance the understanding of the knowledge and to strengthen the capabilities during the whole process of solving problem. These knowledge and abilities will be applied to engineering problems. This teaching mode does not need to reduce the normal class hours; and it can carry out without additional financial support. Students can obtain the background that associate with knowledge and experience. This just responds the educational philosophy of CDIO.

Not only the advanced philosophy of education is needed in education reform, but specific, actionable training objectives and methods are required also. The present mode of "experiencing entire process solving problem" and its detailed training objectives and ways are sustainability and versatility. It can provide references for other curriculum reform.

\section{Acknowledgement}

The present research was sponsored by the Shaanxi Higher Education Reform Project (Project No. 2015-93) and Xi'an Shiyou University 9th Teaching Reform Project (Project No. 2015-3).

\section{References}

[1] L.C. Woollacott. Validating the CDIO syllabus for engineering education using the taxonomy of engineering competencies [J]. European Journal of Engineering Education, 2009( 6), 545-559

[2] Peihua Gu and Cun Huishang. CDIO syllabus and standards (in Chinese) [M]. Shantou University Press, 2008.

[3] Peihua Gu and Nengsheng Bao. CDIO in China (Part I and II) [J]. Research in Higher Education of Engineering (in Chinese), 2012 (3, 5), 24-40,34-45.

[4] Wenlong Hu. On reform of CDIO based Engineering inquiry teaching mode[J]. Research in Higher Education of Engineering (in Chinese), 2014(1), 163-168

[5] Edward Crawley, Johan Malmqvist, William Lucas and Doris Brodeur. The CDIO syllabus v2.0: an updated statement of goals for Engineering Education [C]. Proceedings of the $7^{\text {th }}$ international CDIO conference technical university of Denmark Copenhagen, June20-23, 2011 